DOI 10.37882/2500-3682.2021.02.15

\title{
СРАВНИТЕЛЬНЫЙ АНАЛИЗ ДИНАМИЧЕСКОЙ И ФУНКЦИОНАЛЬНОЙ КОНЦЕПЦИЙ ВРЕМЕНИ
}

\section{COMPARATIVE ANALYSIS OF DYNAMIC AND FUNCTIONAL CONCEPTS OF TIME \\ T. Lolaev \\ A. Gabaraev \\ A. Dryaev}

Summary: In this work, as a result of the comparative analysis of the dynamic and functional concepts of time, the similarities and differences between them in the explication of the concept of time are revealed.

So, in both concepts, events and objects exist in the present time, and the present time arises as a result of qualitative changes occurring in them.

At the same time, there is a difference between the present of the dynamic and the functional concepts: the present of the dynamic concept is a «moment» in time, while in the functional concept the present exists as long as an object exists, a process (each object is a process) that forms its own time.

In a functional concept, as in a dynamic concept, time flows. However, in a dynamic concept, time flows from the past through the present to the future.

Functional time flows from the present to the subsequent present of successively changing, qualitatively new states of the process, as well as from the present of some objects to the present of subsequent objects, which, due to the non-substantial nature of time, begin to form their own present times.

Time, both in dynamic and functional concepts, is associated with becoming. However, according to the functional concept, consistently changing substantive changes occur in the present time, while in the dynamic one they move in time from the past through the present to the future.

There are other similarities and differences between the discussed concepts of time, which are discussed in the article.

Keywords: time; dynamic time; functional time; non-substantial time; present tense; similarities; differences; events; objects.
Лолаев Тотраз Петрович

Д.ф.н., профессор, Северо-Кавказский горно-металлургический институт

(государственный технологический университет)

lolaev.tp@gmail.com

Габараев Анатолий Дмитриевич

К.ф.н., доцент, Юго-Осетинский государственный университет

gabaraev689@gmail.com

Дряев Аквсентий Герисоевич

К.и.н., дочент, Северо-Кавказский горнометаллургический институт

(государственный технологический университет) arssenn26@mail.ru

Аннотация: В данной работе, в результате проведенного сравнительного анализа динамической и функциональной концепций времени, выявлены сходства и различия между ними в экспликации понятия времени.

Так, в обеих концепциях события и объекты существуют в настоящем времени, а настоящее время возникает в результате качественных изменений, происходящих в них.

Вместе с тем между настоящим динамической и функциональной концепций имеется различие: настоящее динамической концепции представляет собой «момент» времени, тогда как в функциональной концепции настоящее существует, пока существует объект, процесс (каждый объект - процесс), образующий свое собственное время.

В функциональной концепции, как и в динамической, время течет. Однако в динамической концепции время течет от прошлого через настоящее к будущему.

Функциональное же время течет от настоящего к последующему настоящему последовательно сменяющихся, качественно новых состояний процесса, а также от настоящего одних объектов к настоящему последующих объектов, которые, по причине несубстанциональности времени, начинают образовывать свои собственные настоящие времена.

Время и в динамической, и в функциональной концепции связано со становлением. Однако, согласно функциональной концепции, последовательно сменяющиеся субстанциональные изменения происходят в настоящем времени, тогда как в динамической - движутся во времени от прошлого через настоящее к будущему.

Между обсуждаемыми концепциями времени имеют место и другие сходства и различия, которые рассматриваются в статье.

Ключевые слова: время; динамическое время; функциональное время; несубстанциональное время; настоящее время; сходства; различия; события; объекты. 
динамической концепции времени существуют только события настоящего, а события прошлого уже реально не существуют.

Имея в виду динамическую концепцию времени, профессор МГУ им. М.В. Ломоносова, профессор В.П. Казарян пишет: «Центральным смыслообразующим понятием времени является понятие настоящего, которое обеспечивает непространственно-подобный смысл времени. Предлагается «настоящее» трактовать как акт (свершение, действие), имеющий социальную природу. «Настоящее» существует не как предмет, не как мысль или чувство, а как акт» [2, с. 36].

По нашему мнению, «настоящее» имеет не только социальную, но и естественную природу.

Понятие настоящего трактуется нами не только как акт, имеющий социальное значение, но и как единственный модус объективного времени вообще, в данном исследовании анализируются философская и научная специфика функциональной и динамической концепции, сходства и различия между ними.

По мнению В.П. Казарян: «Для человечества, пока оно существует, есть «настоящее», а вместе с ним и «прошлое» и «будущее». Другое дело, что речь идет о сфере человеческой жизни, а не о мире, где нет человека. В мире без человечества, возможно, нет «настоящего, прошедшего и будущего», но есть временной порядок «раньше, позже, одновременно»... вопрос о существовании или несуществовании временного становления, или, другими словами, «настоящего», т.е. течения времени, временного потока, справедливо решить положительно для жизни человечества» [2, с. 43].

В.П. Казарян отмечает, что существуют два времени: время для человечества и человека, т.е. время субъективное и время объективное в мире, где нет наблюдателя.

О существовании двух основных подходов к решению проблемы времени говорил и выдающийся французский философ П. Рикер. Он называл их феноменологическим и космологическим, хотя имеются виду субъективный и объективный подходы к проблеме времени [3, с. 335].

Следует согласиться с тем, что для человечества, пока оно существует, всегда будут существовать «настоящее», «прошлое» и «будущее», поскольку они - продукт человеческого сознания.

Вместе с тем, по нашему мнению, в мире, где нет человечества, нет «прошлого» и будущего», есть только настоящее (но только в природе). А вопрос о существовании временного становления, или, другими словами, «настоящего», т.е. течения времени, временного потока, положительно решается в функциональной концепции времени.

Согласно функциональной концепции, если нет человечества, если нет ни «прошлого», ни будущего», ни «настоящего» субъективного времени, есть только настоящее функционального, объективно-реального времени.

Видный специалист по проблеме времени Ю.Б. Молчанов писал: «Динамическая концепция, как известно, признает объективную реальность временных отношений вообще и «течения» времени или «становления» В частности. Вместе с тем, «согласно динамической концепции, реально существуют только события настоящего времени. События прошлого уже реально не существуют. Все множество событий и материальных систем, составляющих Вселенную, движется, так сказать, во времени от прошлого через настоящее к будущему, испытывая становление, возникая и исчезая, превращаясь в другие события и материальные системы. Относительно любого момента настоящего времени все остальные (будущие и прошлые) события непрерывно меняют свое положение. Будущие события становятся все менее будущими и через момент настоящего уходят в прошлое, становясь все более и более прошлым. Момент настоящего времени объективно отделяет реально существующие события от их причинных предков» [4, с. 85].

В объективной реальности существует и время функциональной концепции. Так, согласно функциональной концепции времени, каждый материальный объект, в результате последовательной смены его качественно новых состояний, образует актуальную длительность, специфическим отражением которой является длительность объективно-реального, функционального времени [5].

При движении, как простом перемещении, объективно-реальное, функциональное время не образуется. При механическом движении время возникает лишь в сознании наблюдателя, и поэтому оно является субъективным.

О неразрывной связи и времени писал еще Аристотель: «Ясно, что каким будет движение, таким и время...» [6, с. 149].

Аристотель справедливо указывал как на объективность времени, так и на его несубстанциональность, когда писал, что «время не есть движение, но и не существует без движения» [6, с. 148].

Поскольку функциональное время образуется реальными объектами, имеющими материальное содержание, оно, не являясь физической сущностью, имеет физическое значение.

С нашей точки зрения, время не форма существова- 
ния материи, а функция конкретных материальных объектов [7, с. 123].

Г. Гегель связывал время с объектами, процессами. Он писал: «Вещи исчезают не потому, что они находятся во времени, а потому, что сами они представляют собой временное... Процесс самих действительных вещей, составляет, следовательно, время» $[8$, c. 50].

Г. Гегель также писал: «Во времени, говорят, все возникает и преходит..., но не во времени все возникает и преходит, а само время есть это становление, есть возникновение и прехождение» [8, с. 54].

Согласно Г. Лейбницу: «время без вещей является лишь чисто идеальной возможностью» [9, с. 484].

Академик АН СССР В.И. Вернадский был убежден в объективном существовании времени. Он писал: «Время есть одно из основных проявлений вещества, неотделимое от него его содержание» [10, с. 229].

А. Эйнштейн связал время с реальными физическими процессами, когда писал: «Пространственные и временные данные имеют не фиктивное, а физически реальное значение» [11, с. 24].

Согласно функциональной концепции, материальные объекты, процессы образуют собственные времена, в которых и существуют с возникновения и до воплощения их материального содержания в последующие объекты. В этой связи несубстанциональное время вне объектов, процессов не существует.

В связи с тем, что материальное содержание одних объектов воплощается в другие, а последующие объекты начинают образовывать свои собственные времена, время, в принципе, не может переходить от одного объекта к последующему объекту.

Поскольку время, образуемое объектами несубстанционально, не может переходить от одного объекта к последующему объекту, а вне объектов не существует, оно всегда настоящее.

По указанным причинам, в прошлом и будущем временах нет реальных объектов, процессов, которые образовывали бы свои собственные времена. В этой связи, неправомерно вести речь о существовании в природе прошлого или будущего времени.

Прошлое и будущее времена, как отмечали многие мыслители античности и современные исследователи, возникают и существуют лишь в сознании человека и к объективной реальности не имеют отношения.
Таким образом, в природе существует лишь настоящее время, а потому в объективной реальности возможен только переход от настоящего к последующему настоящему, которое образуется последовательно сменяющимися качественно новыми материальными объектами и их состояниями, а не переход от уже несуществующего прошлого через настоящее к несуществующему ещё будущему или наоборот. Материальное содержание объектов непреходяще, оно постоянно воплощается в другие, последующие объекты, которые необходимо начинают образовывать свои собственные настоящие времена.

Нам представляется, что социальное функциональное время возникает и существует в результате деятельности человека и групп людей различного уровня организации общества, таких как отдельные семьи, население городов, областей, республик и государств. В этой связи правомерно вести речь и о деятельности человечества в целом.

В результате их деятельности возникает и длится, например, настоящее историческое или социальное время. Мы не оговорились, когда назвали историческое время настоящим, поскольку историю творят люди, пока существуют в своем собственном настоящем времени.

Не случайно еще Августин, можно сказать, на заре первого тысячелетия, писал: «Теперь ясно становится для меня, что ни будущего, ни прошедшего не существует и что не точно выражаются о трех временах, когда говорят прошедшее, настоящее и будущее, а было бы точнее, кажется, выражаться так: настоящее прошедшего и настоящее будущего. Только в душе есть соответствующие тому три формы восприятия и не где-нибудь инде (то есть, не в предметной действительности). Так для настоящего прошедших предметов есть у нас память ли воспоминание...для настоящего настоящих предметов есть у нас взгляд, воззрение, созерцание... а для настоящего будущих предметов есть у нас, чаяние, упование, надежда... Говоря таким образом, я не затрудняюсь в понимании тройственности времени...» [12, с. 589].

В этой связи, пользуясь терминологией Августина, история не наука о прошлом, история наука о настоящем прошлого. Иными словами, историческое время это настоящее время прошлых событий и предметов.

Согласно динамической концепции: «Любая материальная система существует в «настоящее время», «сейчас» или «теперь» в единственном экземпляре, и ее изменения представляют собой, грубо говоря, перегруппировку или замену составляющих ее материальных частиц» $[13$, с. 68].

Как было сказано, функциональное время, в отличие 
от динамического, существующего в «настоящее время», «сейчас» или «теперь», существует в настоящем времени, пока существуют образующие его материальные объекты (т.е. до воплощения их материального содержания в последующие объекты).

В любой материальной системе, согласно динамической концепции времени, как и в любом материальном объекте, согласно функциональной концепции времени, происходят качественные изменения.

Другими словами, как в динамической, так и функциональной концепции времени настоящее время образуется исключительно в результате последовательной смены качественных изменений.

Понятие настоящего времени занимает центральное место и в динамической, и в функциональной концепции.

Таким образом, несмотря на различия в представлениях динамической и функциональной концепций, с нашей точки зрения, трудно переоценить научную значимость придания времени статуса реальности Гераклитом и его учениками.

Следует констатировать, что и в наши дни не всеми осознается значение настоящего. Нередко люди, оправдывая свою пассивность или бездеятельность, проводят свое настоящее время в ожидании будущего.

Динамическая концепция признает течение времени, связь его со становлением. Однако, согласно динамической концепции, время течет от прошлого через настоящее к будущему, испытывая становление.

В функциональной концепции время течет от настоящего к последующему настоящему и в его течении прошлое и будущее участия не принимают, поскольку в природе их нет. Функциональное время образуется в результате движения, как причины становления. Речь идет о становлении как субстанциональном изменении, связанном с появлением качественно нового, с возникновением и исчезновением объектов и их состояний, их превращением в другие объекты и состояния, - становлением, при котором нечто несуществующее ранее, становится существующим.

Таким образом, согласно как функциональной концепции, так и динамической, реально существуют только события настоящего времени. Однако множество событий и материальных систем, составляющих Вселенную, в динамической концепции движется во времени от прошлого через настоящее к будущему, а в функциональной концепции, каждое событие и каждая материальная система образует свое собственное настоящее время, пока их материальное содержание не воплотится в последующие события и системы.

Возникшие, но еще не исчезнувшие материальные объекты, системы (каждый объект - система) существуют в своем собственном настоящем времени, пока являются таковыми. В этой связи нельзя согласиться с тем, что относительно любого момента настоящего времени будущие и прошлые события непрерывно меняют свое положение, будто бы будущие события становятся все менее будущими и через момент настоящего уходят в прошлое, становясь все более и более прошлыми. Реально существующие события возникают лишь тогда, когда в них воплощается материальное содержание предыдущих событий. И эти события возникают не из будущего, а из настоящего предыдущих событий и начинают образовывать свое собственные настоящие времена, которые длятся не мгновенно, а с момента возникновения каждого объекта, до воплощения его материального содержания в последующий объект (или последующие объекты).

Здесь следует пояснить, что «момент» настоящего времени, каковым является настоящее в динамической концепции, также является продуктом сознания, а не настоящим, образуемом реальными объектами, существующими в природе.

С тезисом, что время в природе всегда настоящее, исследователи, как правило, не согласны, так как, по их мнению, в этом случае настоящее не течет, а течение времени является его характерной чертой.

С точки зрения американского философа А. Грюнбаума, «деление на прошлое, настоящее и будущее составляет черту сознания и зависит только от выбора субъектом момента времени, обозначаемого им понятия «сейчас» или «теперь» [14, с. 382].

С нашей точки зрения, как и согласно мнению ряда исследователей, идеи античных мыслителей имеют эвристическое значение для всестороннего обоснования объективности времени.

Так, профессор В.Н. Зима, в своей монографии «Проблема объективности времени в философии» сосредоточил свое внимание на ключевых идеях «высказанных рядом философов и в рамках ряда философских традиций, принадлежащих к античной и средневековой философии» $[15$, с.290].

Аналогичного мнения придерживается и членкорреспондент РАН П.П. Гайденко, которая, имея в виду современное истолкование проблемы времени, пишет: «Не утрачиваем ли мы что-то важное и существенное, чем обладало человечество в эпоху метафизики и что оказалось разрушенным сегодня?» [16, с. 308]. 
Ю.Б. Молчанов подчеркивал: «Даже в том случае, если будут найдены окончательные ответы на все вопросы, составляющие проблему времени, но не будет дано ответа на вопрос, какими объективно-реальными параметрами или характеристиками отличается бытие событий прошлого от бытия событий настоящего (а возможно и будущего)... то проблема времени так и останется проблемой, то есть вопросом, на который нужно найти ответ» $[17$, с. 8].

В настоящем исследовании мы попытались ответить на вопросы, поставленные Ю.Б. Молчановым в той мере, в какой позволял нам ограниченный объем журнальной статьи.

В результате проведенного исследования мы пришли к выводу, что понятие настоящего в динамической концепции времени имеет эвристическое значение.

В функциональной концепции, как нам представляется, был выявлен механизм связи времени с движением как качественным изменением и обосновано отсутствие в природе прошлого и настоящего времен, а также «моментов» настоящего времени, а понятие настоящего стало в ней единственным модусом времени.

Настоящее исследование, по нашему мнению, вызовет у читателей дополнительный интерес к изучению других концепций времени, в которых содержаться идеи, истинность которых предстоит доказать.

\section{ЛИТЕРАТУРА}

1. Материалисты Древней Греции. М.: Государственное издательство политической литературы 1955.

2. Казарян В.П. К истолкованию природы динамического времени //. Вестник МГУ. Серия 7. Философия, №2. С. 36.

3. Ricoeur P. Time and Narrative.Vol 3. The University of Chicago Press, Chihcago, L., 1990335 p.

4. Молчанов Ю.Б. Проблема времени и диалектика // Вопросы философии, 1975, №8. С. 85.

5. Лолаев Т.П. Функциональная концепция времени: Диссертация докт. филос. наук - М., 1993. - 273; Лолаев Т.П. «Природа времени или время в природе: Теоретическое и экспериментальное обоснование объективного существования времени». М., 2015

6. Аристотель. Соч. Т. 3. С. 149.

7. Lolaev Totraz. Time is not a Universal Form of Material Being // Twentieth World Congress of Philosophy. Boston, USA. 10-16 August, 1998, p. 123.

8. Гегель Г. Энциклопедия философских наук, т. 2. М., 1975. С. 50.

9. Лейбниц. Переписка с Кларком // Сочинения, М., Т. 1. С. 484.

10. Вернадский В.И. Проблема времени в современной науке // философские мысли натуралиста. М., 1988. С. 229.

11. Эйнштейн А. Собр. науч. трудов. Т. ІІ. 1966. С. 24.

12. Антология мировой философии. Т. 1. Ч. 2. С. 589.

13. Габараев А.Д. Концептуальное содержание проблемы времени. Цхинвал. 2020. С. 68.

14. Грюнбаум А. Философские проблемы пространства и времени. М., 1969. С. 382-383.

15. Зима В.Н. Проблема объективности времени в философии. М.: Прометей. 2019. С.290.

16. Гайденко П.П. Время. Длительность. Вечность. М.: Прогресс-Традиция 2006. С. 308.

17. Молчанов Ю.Б. Проблема времени в современной науке. М., 1990. С. 8.

○ Лолаев Тотраз Петрович (lolaev.tp@gmail.com ), Габараев Анатолий Дмитриевич (gabaraev689@gmail.com ), Дряев Аквсентий Герисоевич (arssenn26@mail.ru).

Журнал «Современная наука: актуальные проблемы теории и практики» 